Document downloaded from:

http://hdl.handle.net/10251/125079

This paper must be cited as:

Scarazzato, T.; Panossian, Z.; Tenorio, J.; Pérez-Herranz, V.; Espinosa, D. (2018). Water reclamation and chemicals recovery from a novel cyanide-free copper plating bath using electrodialysis membrane process. Desalination. 436:114-124.

https://doi.org/10.1016/j.desal.2018.01.005

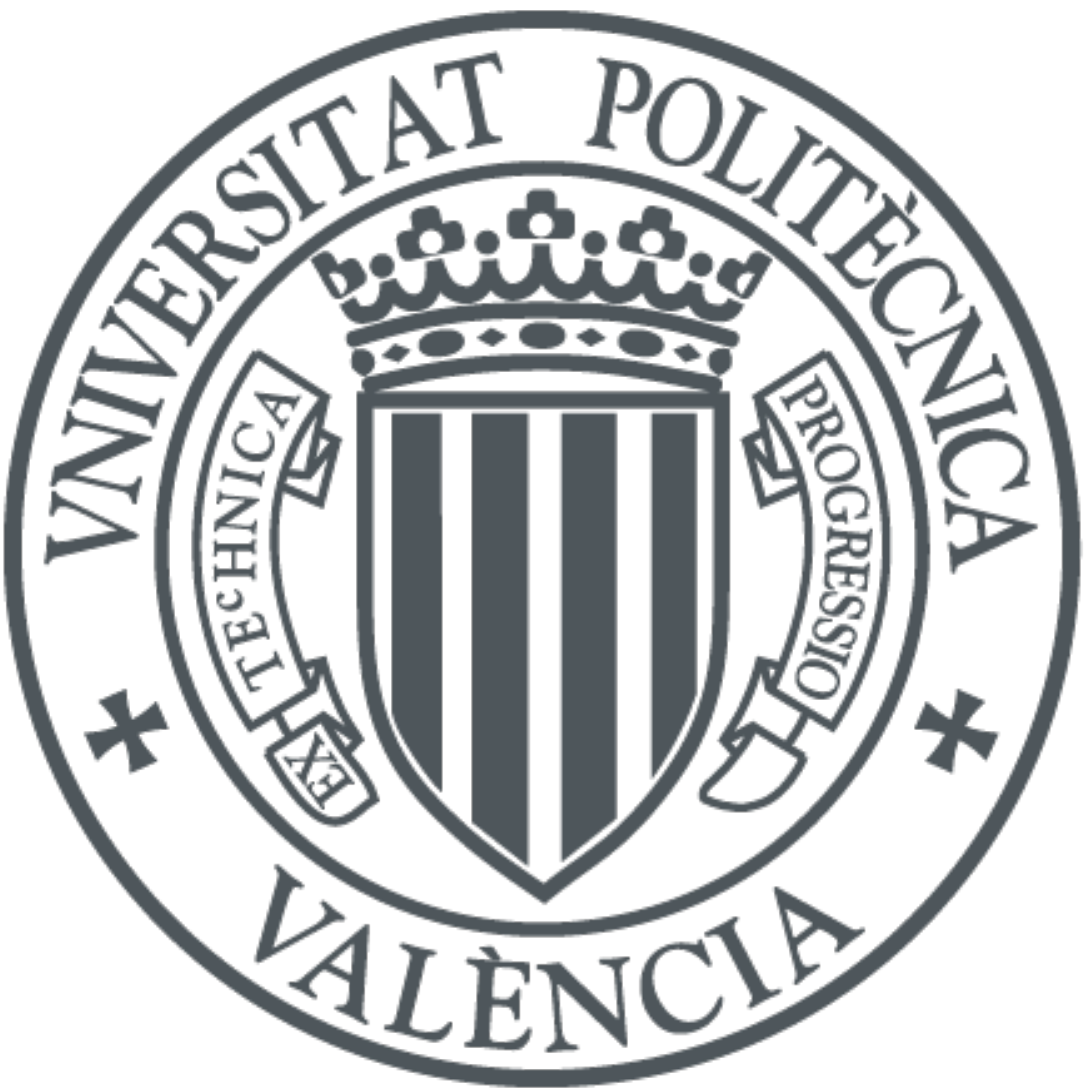

The final publication is available at

http://doi.org/10.1016/j.desal.2018.01.005

Copyright Elsevier

Additional Information 


\title{
Water reclamation and chemicals recovery from a novel cyanide-free copper plating bath using electrodialysis membrane process
}

\author{
T. Scarazzato ${ }^{\text {a,b,d, }}{ }^{*}$, Z. Panossian ${ }^{\text {b,c }}$, J.A.S. Tenório ${ }^{\text {a }}$, V. Pérez-Herranz ${ }^{\text {d, D.C.R. Espinosa }}{ }^{a}$ \\ ${ }^{a}$ Chemical Engineering Department, Universidade de São Paulo, Av. Prof. Lineu Prestes \\ 580, Bloco 18, 05434-070 São Paulo, SP, Brazil \\ ${ }^{\mathrm{b}}$ Institute for Technological Research, Corrosion and Protection Laboratory, Av. Prof. \\ Almeida Prado, 532, 05508-901 São Paulo, SP, Brazil \\ ${ }^{\mathrm{c}}$ Department of Metallurgical and Material Engineering, Universidade de São Paulo, Av. \\ Prof. Mello Moraes, 2463, 05508-030 São Paulo, SP, Brazil \\ ${ }^{\mathrm{d}}$ IEC Group, Departament d'Enginyeria Quimica i Nuclear, Universitat Politècnica de \\ València, Camí de Vera s/n, 46022, València, P.O. Box 22012, E-46071, Spain
}

*Corresponding: T. Scarazzato. E-mail address: tscarazzato@usp.br.

Keywords: Electrodialysis; Water reclamation; Chemicals recovery; Copper chelates; Ion-exchange membranes; Copper coating

\begin{abstract}
One of the industrial concerns is to change procedures into sustainable and cleaner processes. In electroplating, researches have been developed to replace toxic materials for safer alternatives. Cyanide salts are toxic compounds used as complexing agents in alkaline baths. This work focused in a cyanide-free copper alkaline bath developed for copper coating onto zinc alloys. Electrodialysis was evaluated to obtain a concentrated solution from a model rinsing water and simultaneously to treat the effluent for further reuse. Membrane properties after electrodialysis were analyzed, before and after cleaning procedures. Deposition tests were performed using electrolytes containing the recycled inputs and the coatings were analyzed. As results, a solution 5 to 6 times more concentrated than the initial one was obtained. The average demineralization was $90 \%$ and the percent extraction of ions was higher than $80 \%$. Interactions between the organic acid and the exchange groups may affect membrane properties. Nevertheless, FTIR analyses and the applied cleaning procedures showed that bonds between phosphorus and quaternary amine may be reversible. Both cleaning procedures presented similar performance and partially restored the membrane properties. The concentrate could be added to the copper bath to compensate eventual drag-out losses without affecting the quality of the coatings.
\end{abstract}

\section{Introduction.}

Electroplating baths are generally categorized in four main groups: acid baths composed of simple salts, acid baths composed of complex salts, alkaline baths composed of metals forming amphoteric salts and alkaline baths composed of complex salts. The latter represents the most common applications of cyanide salts in plating baths. Cyanidebased baths are mostly used for coating parts with complex geometry because they present greater penetration in comparison with acid baths. They are also used to coat parts in which the substrate is less noble tan the coating metal [1]. Because of the toxicity 
associated to cyanide salts, alternative raw materials have been studied in order to obtain metal coatings with similar properties than cyanide-based baths but using non-toxic compounds. Although cyanide salts are considered low cost raw materials, the replacement of cyanide may be economically feasible if the alternative raw material is possible to be reused. The general treatment of wastewaters containing cyanide complexes involves cyanide oxidation to cyanate, resulting in loss of raw materials. Therefore, if the substituent compound can be recovered and reused, costs may become competitive.

The starting point of this work is a cyanide-free copper alkaline bath developed for copper coating onto zinc alloy die castings in barrel plating systems [2] which composition is shown in Table 1.

Table 1. Composition and operating parameters of the HEDP-based strike copper bath [2].

\begin{tabular}{lll}
\hline & & Unit \\
\hline $\mathrm{Cu}^{2+}$ & 4.5 & $\mathrm{~g} \cdot \mathrm{L}^{-1}$ \\
$\mathrm{HEDP}$ & 105.0 & $\mathrm{~g} \cdot \mathrm{L}^{-1}$ \\
$\mathrm{KCl}$ & $4.0-7.0$ & $\mathrm{~g} \cdot \mathrm{L}^{-1}$ \\
Salicyl-sulfonic acid (optional) & 4.0 & $\mathrm{~g} \cdot \mathrm{L}^{-1}$ \\
Potassium sulfate (optional) & 4.0 & $\mathrm{~g} \cdot \mathrm{L}^{-1}$ \\
pH & 10 & - \\
Current density & $0.2-0.5$ & $\mathrm{~A} \cdot \mathrm{dm}^{-2}$ \\
Temperature & $25-60$ & ${ }^{\circ} \mathrm{C}$ \\
Agitation & present & - \\
\hline
\end{tabular}

Throughout the last years, researches [3-8] have shown that the application of electrodialysis for treating electroplating wastewaters can support the wastewater treatment by promoting water reclamation, recovery of metals and other raw materials and, consequently, enhancing the extension of the bath operational life, since the concentrated solutions can be reinserted in the bath tanks. Moreover, it can be a measure to waste minimization and to the reduction of raw material consumption. Among the membrane separation techniques, electrodialysis is the process that uses an electrical potential difference to separate the solute from the solvent. The choice for the most suitable process is performed based on the size and molecular weight of the particles to be removed. Reverse osmosis and electrodialysis are feasible techniques for metal ion removal, while microfiltration (MF), ultrafiltration (UF), nanofiltration (NF) are suitable for aqueous salts and particles having size between $0.005 \mu \mathrm{m}$ and $1.0 \mu \mathrm{m}$. Depending on the application, electrodialysis may present other advantages over reverse osmosis, such as the operation at low pressure, the possibility of separating cations from anions and the possibility of performing partial desalination $[9,10]$.

The simulated wastewater evaluated in this study contains organic chelates formed between copper and HEDP which is a condition that needs further investigation since researches considering the formation of chelates are scarcer. Therefore, the behavior of copper chelates in a laboratory-scale electrodialysis system was analyzed. The possibility 
of obtaining a concentrated solution able to replace ions from the original bath was investigated and the quality of the obtained coatings was evaluated. Thus, the main goal of the contributions of the present study is to evaluate the feasibility of the wastewater treatment from the HEDP-based bath aiming at a closed system in which the water treatment and the raw materials recovery could be simultaneously achieved. In an electrodialysis system, an electric potential difference (or an electric current density) is applied between two poles - cathode and anode. Ion exchange membranes are paralleled positioned between the poles forming individual compartments. The solutions of interest are circulated through the compartments while the electric current density from an external source is applied to the poles. Cations from the solution are transported towards the cathode while anions are transferred towards the anode. The membranes may be cation-exchange (CEM) (allow cations to pass through and retain anions) or anionexchange (AEM) (allow anions to pass through and retain cations). Consequently, more concentrated or more diluted solutions than the original solution are formed [11]. Fig. 1 shows a representation of the principle of electrodialysis.

The ED stack in Fig. 1 shows two electrodes that are separated from each other by cationexchange and anion-exchange membranes. The system is fed with the solution to be treated along with an electrode solution whose function is to maintain the electrical conductivity and to protect the electrodes. Cations and anions are transferred from the diluted compartments to the concentrated compartments through the ionexchange membranes. In the lower part of Fig. 1, the obtained solutions are indicated (treated solution and concentrated solution).

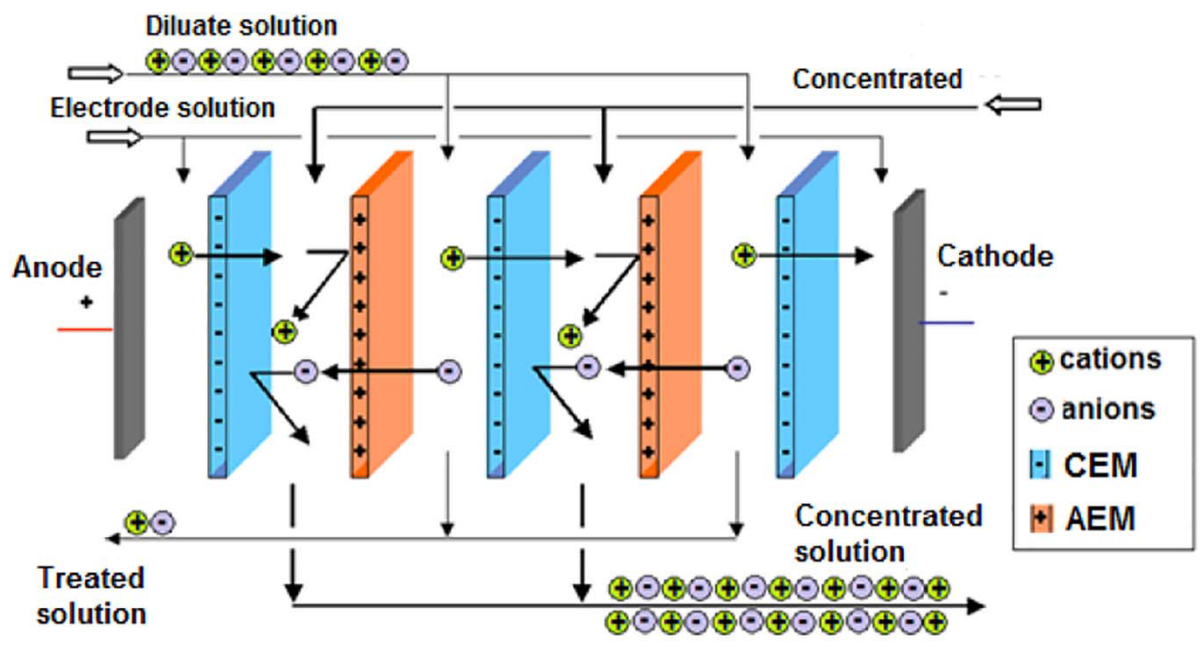

Fig. 1. Representation of electrodialysis [11].

In our previous study [12], the possibility of treating synthetic wastewaters from the mentioned bath by using electrodialysis was proposed. The performed study allowed a percent extraction up to $99 \%$ of ions from the synthetic waste and no membrane clogging was observed. Because of the percent extraction achieved previously, this work contains a more detailed investigation for closing the loop in the electrodialysis application for the evaluated bath. The objective of this work is to evaluate the possibility of obtaining a concentrated solution from a synthetic rinsing water based on the cyanide-free copper bath. The results were evaluated in terms of: percent extraction of each component from the synthetic rinsing water, percent demineralization (to analyze the reusable treated water) and percent concentration, that is, the quantitative copper-HEDP recovery. The 
properties of the anionexchange membrane were evaluated after electrodialysis and after two different cleaning procedures. Lastly, the effectiveness of returning the concentrated solution to the bath was evaluated by preparing mixtures of electrolytes containing the concentrated obtained by electrodialysis. The mixed electrolytes were applied in electrodeposition tests and the obtained copper coatings were analyzed by means of visual tests, adherence tests and SEM/EDS analyses.

\section{Experimental}

\subsection{Electrodialysis bench system}

Tests were carried out in a laboratory-scale bench system containing five individual compartments separated from each other by $16 \mathrm{~cm}^{2}$ rubber spacers and cation and anion exchange membranes $(4 \mathrm{~cm} \times 4 \mathrm{~cm})$ alternately arranged in a "Cathode-A-C-A-C-Anode" configuration. The characteristics of the membranes were described elsewhere [12]. Five $8 \mathrm{~cm} \times 8 \mathrm{~cm} \times 1 \mathrm{~cm}$ compartments were connected to three $1 \mathrm{~L}$ independent reservoirs dilute, concentrate and electrode - containing $1 \mathrm{~L}$ of the working solutions. The solutions under investigation were circulated through the compartments with the aid of centrifugal pumps $\left(3.5 \mathrm{~L} \cdot \mathrm{h}^{-1}\right)$. Titanium electrodes coated with titanium and ruthenium oxides $\left(70 \mathrm{RuO}_{2} / 30 \mathrm{TiO}_{2}\right)$ with an effective area of $16 \mathrm{~cm}^{2}(4 \mathrm{~cm} \mathrm{x} 4 \mathrm{~cm})$ were placed at the extremities and connected to an external power source. The limiting current density was established as presented in a previous study [13]. Electrodialysis tests were carried out at $80 \%$ of the established limiting current density. A schematic representation of the ED system is presented in Fig. 2.

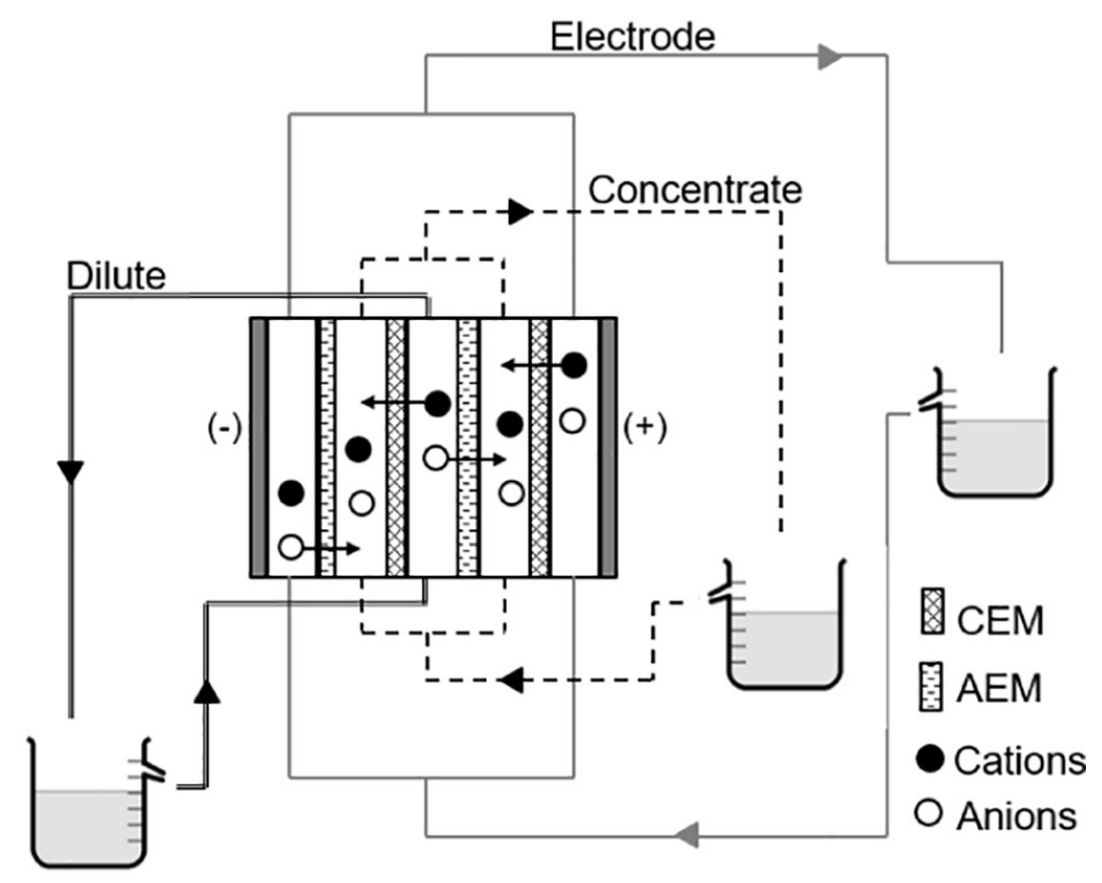

Fig. 2. Schematic representation of the electrodialysis bench system. 


\subsection{Working solutions}

The synthetic solution simulating the rinsing waters from the copper cyanide-free bath was prepared by the dilution of the strike bath itself in a $1 \% \mathrm{v} / \mathrm{v}$ proportion in distilled water. The model solution composition is shown in Table 2.

Table 2. Composition of the synthetic rinsing water.

\begin{tabular}{ll}
\hline Compounds & Synthetic wastewater \\
\hline $\mathrm{HEDP}$ P.A. & $1.05 \mathrm{~g} \cdot \mathrm{L}^{-1}$ \\
$\mathrm{CuSO}_{4} .5 \mathrm{H}_{2} \mathrm{O}$ & $0.1768 \mathrm{~g} \cdot \mathrm{L}^{-1}\left(0.045 \mathrm{~g} \mathrm{Cu}^{2+} \cdot \mathrm{L}^{-1}\right)$ \\
$\mathrm{KCl}$ & $0.070 \mathrm{~g} \cdot \mathrm{L}^{-1}$ \\
$\mathrm{KOH} 50 \%$ & For $\mathrm{pH}$ adjustment $(\mathrm{pH} \approx 10)$ \\
Conductivity & $1.72 \mathrm{mS} \cdot \mathrm{cm}^{-1}$ \\
\hline
\end{tabular}

The synthetic wastewater was used to feed both dilute and concentrate compartments at the beginning of the concentration tests. In order to maintain the conductivity of the system, potassium sulfate solutions $\left(\mathrm{K}_{2} \mathrm{SO}_{4} 3.0 \mathrm{~g} \cdot \mathrm{L}^{-1}\right)$ were used to feed the electrolyte compartment. The $\mathrm{K}_{2} \mathrm{SO}_{4}$ solution conductivity was $3.14 \mathrm{mS} \cdot \mathrm{cm}^{-1}$, about 2 times higher than the conductivity of the synthetic wastewater, to reduce the system ohmic drop.

\subsection{Experimental procedure}

Electrodialysis was performed in long-term concentration tests in order to obtain a concentrated solution and simultaneously produce uncontaminated water. At the beginning of the tests, both dilute and concentrate compartment were fed with the synthetic wastewater. Tests were conducted until the conductivity of the dilute compartment was lower than $200 \mu \mathrm{S} \cdot \mathrm{cm}^{-1}$. When this condition was reached, the treated solution of the dilute compartment was replaced by the synthetic wastewater again. This procedure characterized one "operating cycle". During the tests, the total stack potential, the $\mathrm{pH}$ and the conductivity of all compartments were monitored. The operating cycles were repeated until the ion transfer was limited by the conductivity gradient between the concentrated and the diluted compartments. At the end of each operating cycle, the treated solution and $10 \mathrm{~mL}$ samples of the concentrate solution were collected and forwarded to chemical analysis.

The obtained results were evaluated in terms of percent extraction $(\mathrm{E} \%)$, percent demineralization (D\%) and percent concentration (PC\%) according to Eq. (1) to Eq. (3).

$$
\begin{aligned}
& E \%=1-\frac{C_{t}^{j}}{C_{0}^{j}} \\
& D R \%=1-\frac{E C_{f}}{E C_{0}} \\
& P C \%=\frac{C_{t}^{j}}{C_{0}^{j}}-1
\end{aligned}
$$


$\mathrm{C}_{0 \mathrm{j}}$ and $\mathrm{C}_{\mathrm{tj}}$ are ion concentrations in the initial state and at a given time, respectively. The initials $\mathrm{EC}_{0}$ and $\mathrm{EC}_{\mathrm{t}}$ represents the solution conductivity in the initial state and at a given time $t$, respectively.

\subsection{Analysis of HEDP degradation}

HEDP degradation was evaluated in terms of phosphate conversion. For this study, HEDP degradation is an undesirable reaction since chelates may dissociate and release copper ions. Samples of the initial and final solutions were analyzed for organic HEDP and inorganic orthophosphate, based on the conversion reaction proposed by Steber and Wierich [14] which states that HEDP is degraded into acetate and orthophosphate.

\subsection{Analysis of the membrane electrochemical properties}

The electrochemical properties of the anion-exchange membrane were evaluated by means of chronopotentiometric measurements after electrodialysis tests. The membrane reactor used in this study was well defined in a previous work [15]. Nevertheless, a schematic drawing of the reactor is presented in Fig. 3.

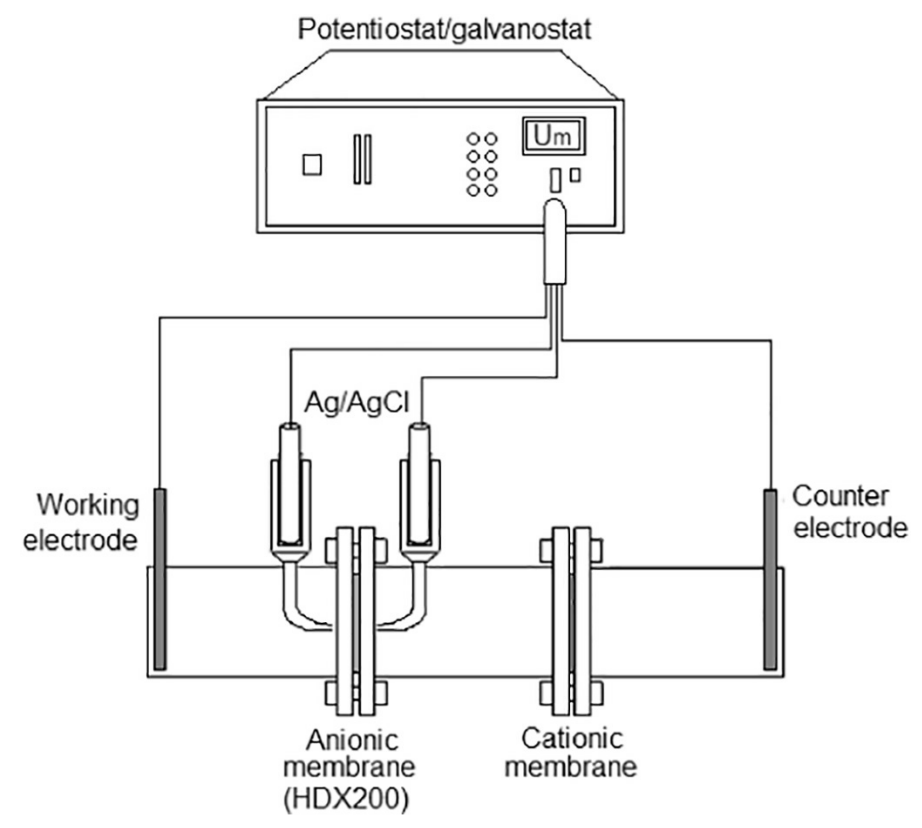

Fig. 3. Membrane reactor used in the chronopotentiometric tests [15].

The reactor was manufactured in polymethyl methacrylate and both working and counter electrodes were graphite made. In all experiments, the three compartments were filled with the solution which composition was presented in Table 2. The electrochemical properties were analyzed for different membrane samples: a virgin, a sample immediately after the electrodialysis test, a sample after acid cleaning and a sample after alkaline cleaning to evaluate the possibility of recovering the original features of the membranes after long-term concentration tests.

The cleaning procedures consisted in immersing the membrane after the electrodialysis test in a sequence of cleaning solutions, as following: ED test $\rightarrow$ rinsing with deionized water $\rightarrow$ cleaning solution during $72 \mathrm{~h} \rightarrow$ deionized water during $24 \mathrm{~h} \rightarrow$ synthetic copper 
rinsing water during $24 \mathrm{~h}$ for steady-state achievement. Two different cleaning solutions were tested. The acid cleaning solution was composed of $\mathrm{H}_{2} \mathrm{SO}_{4}\left(0.1 \mathrm{~mol} \cdot \mathrm{L}^{-1}\right)$ and the alkaline cleaning solution was composed of $\mathrm{KOH}\left(0.1 \mathrm{~mol} \cdot \mathrm{L}^{-1}\right)$. The cleaning solutions were forwarded to chemical analysis to determine the concentration of copper and HEDP that remained in the membrane. The results were compared in order to analyze the performance of the cleaning procedure.

The chronopotentiometric measurements were performed at room temperature with no stirring at different current densities, according to Table 3. Each current density was applied to the assembly during $300 \mathrm{~s}$ while the membrane potential $\left(\mathrm{U}_{\mathrm{m}}\right)$ was registered. After $300 \mathrm{~s}$, the current was interrupted and the system relaxation was registered for additional $100 \mathrm{~s}$. The applied current density along with the potential response as a function of time allowed the construction of currentvoltage curves, from which the transport properties of ions across the membrane were evaluated.

After the chronopotentiometry tests, the membrane sample was analyzed by means of FTIR-ATR spectroscopy to evaluate possible modifications in its structure.

Table 3. Current densities applied for each sample during chronopotentiometric measurements.

\begin{tabular}{ll}
\hline Sample & $\mathrm{i}\left(\mathrm{mA}^{\left.-\mathrm{cm}^{-2}\right)}\right.$ \\
\hline Virgin sample & $0.00 ; 0.03 ; 0.06 ; 0.09 ; 0.11 ; 0.14 ; 0.17 ; 0.20 ; 0.23 ; 0.26 ; 0.28 ; 0.31 ; 0.34 ; 0.37 ; 0.40 ; 0.43 ; 0.45 ; 0.50 ; 0.54 ; 0.58 ; 0.63 ; 0.67 ; 0.71 ; 0.75 ; 0.80 ; 0.85 ; 0.99 ;$ \\
& 1.14 \\
After ED test & $0.00 ; 0.03 ; 0.06 ; 0.09 ; 0.11 ; 0.14 ; 0.17 ; 0.20 ; 0.23 ; 0.26 ; 0.28 ; 0.31 ; 0.34 ; 0.40 ; 0.45$ \\
After H2SO4 cleaning & $0.00 ; 0.03 ; 0.06 ; 0.09 ; 0.11 ; 0.14 ; 0.17 ; 0.20 ; 0.23 ; 0.26 ; 0.28 ; 0.31 ; 0.34 ; 0.37 ; 0.40 ; 0.43 ; 0.45 ; 0.48 ; 0.51 ; 0.54 ; 0.57 ; 0.63 ; 0.68 ; 0.74$ \\
After KOH cleaning & $0.00 ; 0.07 ; 0.14 ; 0.21 ; 0.28 ; 0.36 ; 0.43 ; 0.50 ; 0.57 ; 0.64 ; 0.71 ; 0.78 ; 0.85 ; 0.92 ; 0.99 ; 1.07 ; 1.14 ; 1.28 ; 1.42 ; 1.56 ; 1.70 ; 1.85 ; 1.99 ; 2.13 ; 2.27$ \\
\hline
\end{tabular}

\subsection{Analytical methods}

Copper and HEDP concentrations were determined by energy dispersive X-ray fluorescence spectrometry (PANalytical Epsilon 3XL). Analyses of potassium $\left(\mathrm{K}^{+}\right)$, sulfate $\left(\mathrm{SO}_{4}{ }^{2-}\right)$, phosphate $\left(\mathrm{PO}_{4}{ }^{3-}\right)$ and chloride $\left(\mathrm{Cl}^{-}\right)$were performed by ion cromatography (IC Metrohm 858) using a Metrosep A Supp 5-150/4.0 anion exchange column and a Metrosep C 4-150/4.0 cation exchange column.

During the concentration tests, the $\mathrm{pH}$ of the solutions was monitored with the aid of a Hanna PH21 pHmeter, while the solutions conductivity was measured with a Sensoglass electrical conductivity meter.

The FTIR-ATR spectroscopy analysis of the anion-exchange membrane was performed in a Shimadzu IR Prestige-21 spectroscope, between $700 \mathrm{~cm}^{-1}$ and $4000 \mathrm{~cm}^{-1}$, with 70 scans at $2 \mathrm{~cm}^{-1}$ resolution.

The SEM/EDS analyses were carried out in a Quanta FEG (Field Emission Gun) from FEI Company with an accelerating voltage of $20 \mathrm{kV}$ and a BSE detector for SEM images and an accelerating voltage of $30 \mathrm{kV}$. Dispersive Energy Spectroscopy (EDS) was used for qualitative characterization of the samples.

\subsection{Electrodeposition tests}


Electrodeposition tests were performed to analyze the copper coatings produced when using the HEDP-based bath containing the concentrate obtained by electrodialysis as electrolyte. The aim of these tests was to simulate the replenishment of the original bath with the recovered solution instead of using fresh water and chemicals. The adherence and the visual aspect of the coatings were evaluated by means of SEM/EDS analysis and adherence tests.

The test specimens were manufactured from Zamak ingots and had an effective area approximately equal to $19 \mathrm{~cm}^{2}$. The electrodeposition cell was. The electrodeposition cell was composed of a $100 \mathrm{~mL}$ glass beaker containing $90 \mathrm{~mL}$ of the electrolyte. The test specimen was used as cathode $\left(\right.$ Area $\approx 19 \mathrm{~cm}^{2}$ ) and a copper plate (Area $\approx 50 \mathrm{~cm}^{2}$ ) was used as anode. Both cathode and anode were connected to a potentiostat/galvanostat to provide a more precise control of the applied current density. The electroplating tests were carried out using electrolytes containing the HEDP-based bath and the concentrate solution obtained by electrodialysis in different ratios, between $0 \%$ and $50 \% \mathrm{v} / \mathrm{v}$.

Previously to the electrodeposition tests, the surface of the test specimens was pretreated with the aid of mechanical and chemical

procedures, as follows:

- Surface degreasing using acetone P.A.;

- Wet grinding with a 320 grit $\mathrm{SiC}$ sandpaper;

- Wet grinding with a 400 grit $\mathrm{SiC}$ sandpaper;

- Wet grinding with a 600 grit $\mathrm{SiC}$ sandpaper;

- Rinsing with distilled water;

- Rinsing with ethanol P.A.;

- Hot-air drying;

- Surface degreasing using acetone P.A.;

The test specimens were weighed and stored in a glass vacuum desiccator until the activation and deposition steps. The surface activation was carried out by maintaining the tests specimens under room atmosphere during $24 \mathrm{~h}$, followed by the immersion in a $\mathrm{H} 2 \mathrm{SO} 41 \% \mathrm{v} / \mathrm{v}$ solution for $30 \mathrm{~s}$. The deposition procedure consisted of the immersion of the activated test specimens in $90 \mathrm{~mL}$ of the electrolyte during $10 \mathrm{~min}$ with no electrical current followed by the application of $0.3 \mathrm{~A} \cdot \mathrm{dm}^{-2}$ for $15 \mathrm{~min}$ at room temperature with magnetic stirring. A minimum number of two test specimens were tested for each electrolyte.

Once coated, the test specimens were analyzed to evaluate the aspect and the adherence of the copper layers. The analyses were performed by means of visual tests, SEM/EDS microscopy and adherence tests. To perform adherence tests, each copper coating was carved using a retractable blade knife, creating an X-shaped cut on the test specimen surface deep enough to achieve the Zamak substrate. Then, an adhesive tape (3 M, model $880 \mathrm{Scotch}$ ) was coated onto the carved surface and vigorously rubbed with an ordinary rubber to ensure a complete adhesion between the tape and the surface. The tape was rapidly pulled in a parallel direction of the test specimen surface. The evaluation of the adherence was performed qualitatively, by analyzing the detachment of the copper layer when pulling the tape. Lastly, SEM/EDS analyses were carried out to evaluate the uniformity of the copper coatings. 


\section{Results and discussion}

Electrodialysis was performed in long-term concentration tests using the laboratory-scale system previously presented in Fig. 2. Fig. 4 shows the conductivities of concentrate and dilute solutions throughout the operating time. At the end of each operating cycle, the percent desalination was calculated. It was observed that after each of the 5 operating cycles, the percent demineralization was higher than $90 \%$, which is also noticed from the conductivity of the dilute solutions that achieved values below $200 \mu \mathrm{S} \cdot \mathrm{cm}^{-1}$. During the latter operating cycle, the percent demineralization decreased to about $45 \%$. This behavior may be attributed to the conductivity gradient formed between the concentrate and the dilute compartment. Note that, at the beginning of the sixth cycle, the conductivity in the concentrate compartment was near $18 \mathrm{mS} \cdot \mathrm{cm}^{-1}$. The high ion concentration in the concéntrate compartment favored the diffusion from the concentrate towards the dilute compartment. The operating time and the number of operating cycles are also related to the dimensions of the electrodialysis system and to the effective membrane area. Nevertheless, when the diffusion becomes more important than migration, the ion removal from the dilute compartment is suppressed.

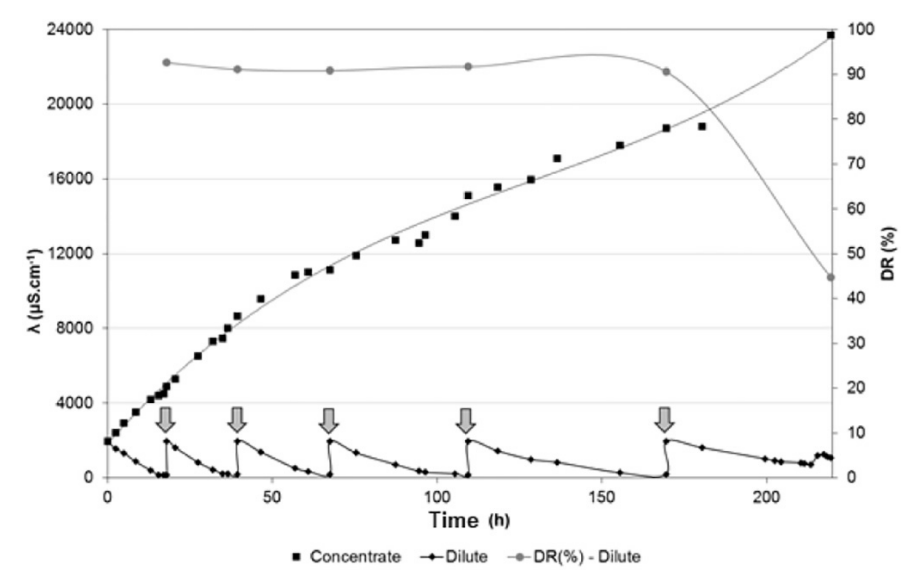

Fig. 4. Conductivity of the solutions from the concentrate compartment, dilute compartment and the percent demineralization $(\mathrm{D} \%)$ at the end of each operating cycle. The grey arrows indicate the beginning of a new operating cycle.

The percent extraction of each component of the synthetic rinsing water is presented in Fig. 5.

The results from Fig. 5 showed a similar tendency as those presented in Fig. 4. During the first three operating cycles, the percent extraction for all ions showed to be near $90 \%$. During the fourth cycle, sulfate anions started to present a decreasing tendency. It is noteworthy that the duration of each operating cycle was longer than the immediately previous cycle. This indicates that, the greater conductivity gradient between the concentrate and the dilute compartment decreases the mobility of ions towards the concentrate. In the sixth operating cycle, the percent extraction of all components was lower than $70 \%$. In addition, the percent extraction of sulfate anions could not be established, because of the back diffusion of sulfate to the dilute compartment. 


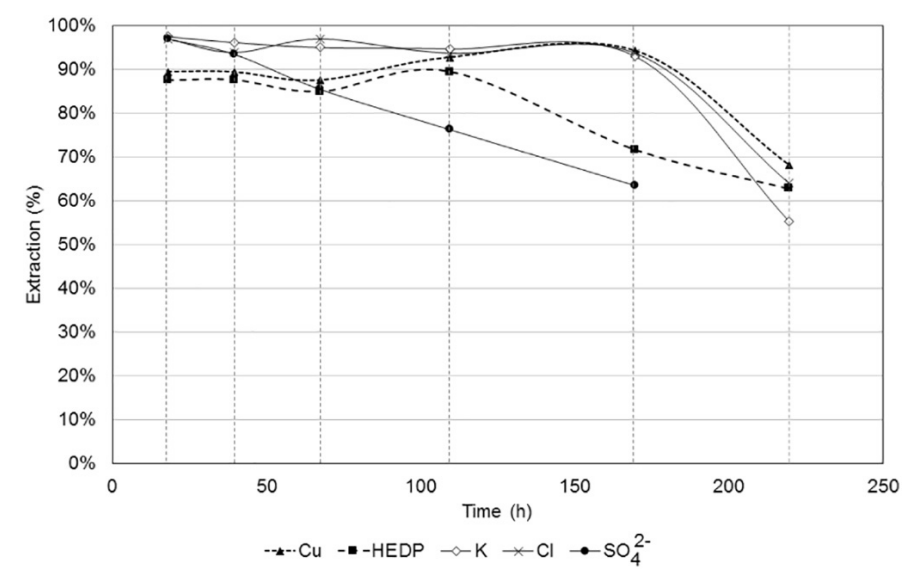

Fig. 5. Percent extraction of copper, HEDP, potassium, chloride and sulfate from the dilute compartment at the end of each operating cycle.

The percent concentration depicts the effectiveness of the electrodialysis in concentrating each component from the solution. The obtained results from copper, HEDP and chloride anions are presented in Fig. 6.

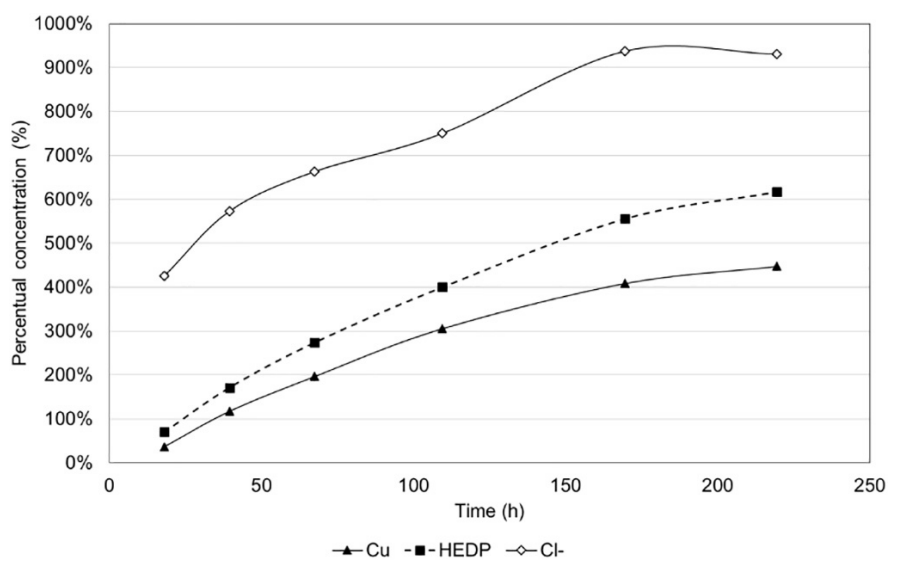

Fig. 6. Percent concentration for copper, HEDP and chloride during electrodialysis test.

The greater percent concentration of chloride anions may be attributed to their higher mobility in solution and inside the membrane. Copper concentration was less efficient than chloride and HEDP anions because copper is transferred as organic chelates, which present greater size and lower mobility than the other anions. In Fig. 6, the concentration of sulfate and potassium were not taken into account because both ions were also transferred to concentrate from the electrode compartment. The composition of the obtained concentrate solution in comparison with the synthetic rinsing water and the copper bath in presented in Fig. 7.

In Fig. 7, it is important to observe that the increase on the concentration of sulfate and potassium is influenced by the transport of ions from the electrode compartments towards the concentrate compartments. The conductivity of the electrodes compartment decreased throughout time because of the combination between the auto-ionization of water, the reduction of hydrogen and the oxidation of oxygen. Therefore, $\mathrm{K}_{2} \mathrm{SO}_{4}$ was periodically added to the electrodes compartment to adjust the conductivity and reduce the ohmic 
drop, which contributed for the increase of the concentration of potassium and sulfate in the concentrate compartment.

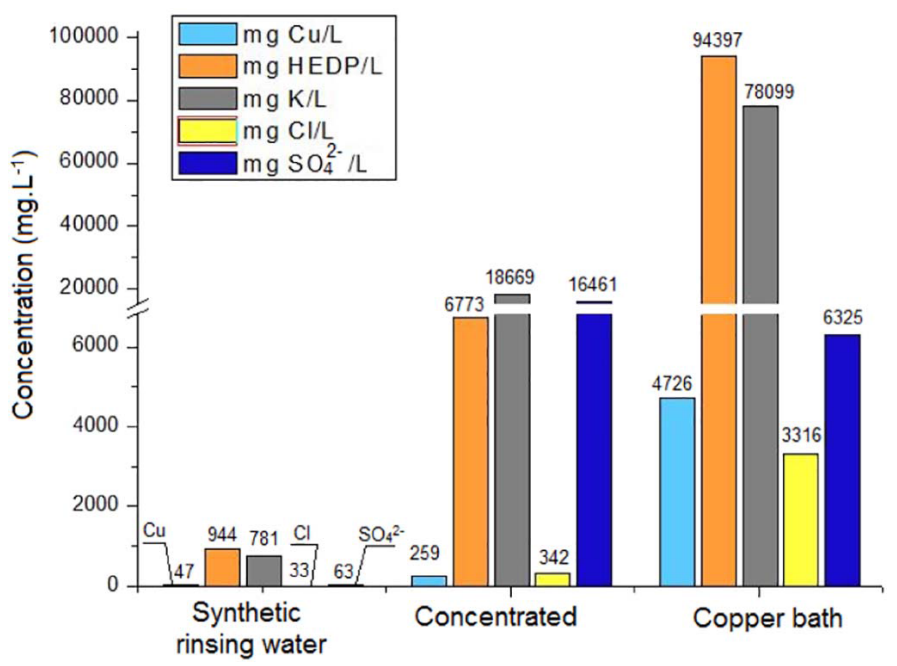

Fig. 7. Composition of the initial synthetic rinsing water, of the copper bath and of the obtained concentrated solution after ED test.

The composition of the treated solutions after each of the operating cycles is presented in Table 4.

Table 4. Composition of the treated solutions after each electrodialysis operating cycle.

\begin{tabular}{llllllll}
\hline Solution & \multicolumn{3}{l}{ Concentration $\left(\mathrm{mg} \cdot \mathrm{L}^{-1}\right)$} & & $\mathrm{pH}$ & $\lambda\left(\mu \mathrm{S} \cdot \mathrm{cm}^{-1}\right)$ \\
\cline { 2 - 6 } & $\mathrm{Cu}$ & $\mathrm{HEDP}$ & $\mathrm{K}$ & $\mathrm{Cl}^{-}$ & $\mathrm{SO}_{4}{ }^{2-}$ & & \\
\hline Dilute (1 st cycle) & 5 & 118 & 20 & 1 & 2 & 3.72 & 145 \\
Dilute (2nd cycle) & 5 & 117 & 30 & 2 & 4 & 3.77 & 174 \\
Dilute (3rd cycle) & 6 & 142 & 39 & 1 & 9 & 3.79 & 180 \\
Dilute (4th cycle) & 3 & 99 & 41 & 2 & 15 & 4.06 & 163 \\
Dilute (5th cycle) & 3 & 267 & 54 & 2 & 23 & 4.46 & 183 \\
Dilute (6th cycle) & 15 & 351 & 348 & 12 & 235 & 7.22 & 1083 \\
Concentrated & 259 & 6773 & 18,700 & 342 & 16,460 & 8.95 & 23,700 \\
\hline
\end{tabular}

In Fig. 8, the visual aspect of the solutions before and after electrodialysis is presented. The synthetic rinsing water was the initial solution used in both dilute and concentrate compartments before beginning the electrodialysis test. The treated solution is one of the treated solution from the dilute compartment after achieving a conductivity below 200 $\mu \mathrm{S} \cdot \mathrm{cm}-1$. Finally, the concentrate is the solution obtained after all operating cycles and which composition was presented in Fig. 7.

From the abovementioned results, after 5 operating cycles, the concentration gradient between the concentrate and the dilute compartment caused an undesirable backward diffusion. As a consequence, an energy waste may occur, since the applied energy would be used to overcome the backwards diffusion and to transfer mainly sulfate and potassium which are not the anions of major interest. 


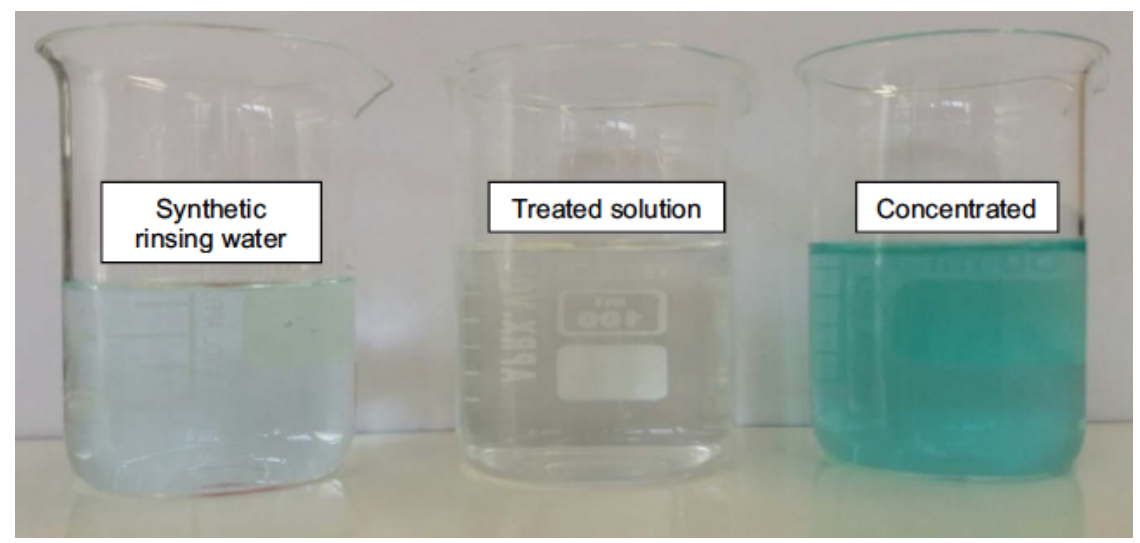

Fig. 8. Visual aspect of the synthetic rinsing water used at the beginning of ED, the treated solution after one ED operating cycle and the final concentrate obtained after

ED.

Thus, a similar electrodialysis test was carried out with 5 complete operating cycles. The percent demineralization and the final composition of the treated solutions and the concentrate solution were compared to the previous test. Fig. 9 shows the conductivity of the diluted solutions after each of the 5 cycles, the percent demineralization achieved at the end of each cycle and the increase of the conductivity of the concentrate solution during the test. Fig. 10 shows the extraction of copper, HEDP, sulfate, potassium and chloride from the diluted compartment at the end of each of the 5 operating cycles.

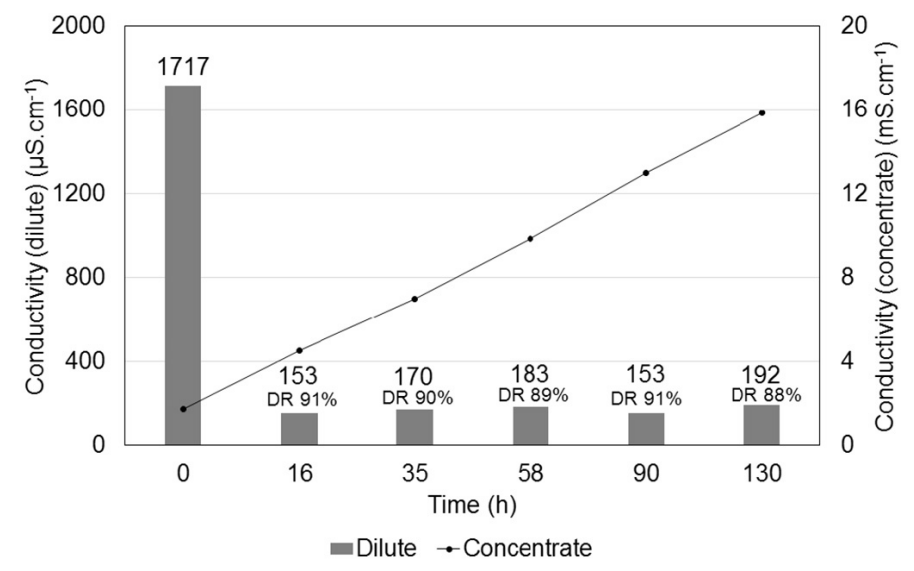

Fig. 9. Conductivity of the treated solutions and the concentrate solution during the longterm electrodialysis test performed in continuous system for 5 operating cycles. The percent demineralization at the end of each cycle is indicated below the conductivity of dilute solutions. 


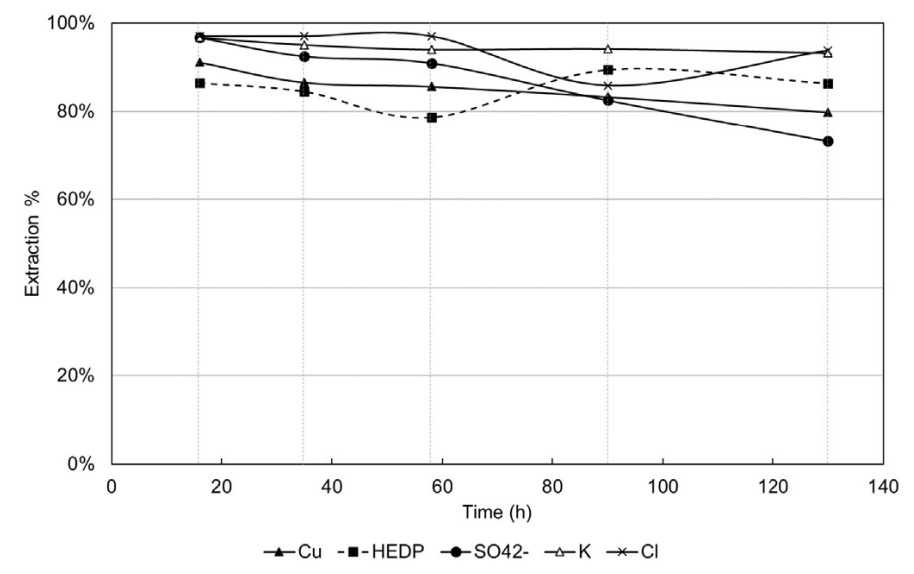

Fig. 10. Percent extraction of copper, HEDP, potassium, chloride and sulfate from the dilute compartment during the long-term electrodialysis test performed in continuous system for 5 operating cycles.

Figs. 9 and 10 show that the behavior of the system was similar to the observed previously, achieving percent demineralization and ion extraction near $90 \%$ for all treated solutions. In addition, the backwards diffusion could be suppressed which improved the system efficiency. The composition of the solutions obtained after the five-cycle electrodialysis test is shown in Table 5.

Table 5. Composition of the treated solutions and the final concentrated solution after the fivecycle electrodialysis test.

\begin{tabular}{llllllllll}
\hline \multirow{2}{*}{ Solution } & $\mathrm{D}(\%)$ & $\lambda\left(\mu \mathrm{S} \cdot \mathrm{cm}^{-1}\right)$ & $\mathrm{pH}$ & \multicolumn{6}{l}{ Concentration $\left(\mathrm{mg} \cdot \mathrm{L}^{-1}\right)$} \\
\cline { 5 - 9 } & & & & & $\mathrm{Cu}^{2+}$ & $\mathrm{HEDP}$ & $\mathrm{K}^{+}$ & $\mathrm{Cl}^{-}$ & $\mathrm{SO}_{4}{ }^{2-}$ \\
\hline I & 91.1 & 153 & 3.66 & 4.3 & 131 & 25 & $<1$ & 2.2 \\
II & 90.1 & 170 & 3.81 & 6.6 & 150 & 38 & $<1$ & 5.1 \\
III & 89.3 & 183 & 3.58 & 7.0 & 207 & 46 & $<1$ & 6.2 \\
IV & 91.1 & 153 & 4.16 & 8.2 & 102 & 45 & 4.9 & 11.9 \\
V & 88.9 & 192 & 4.11 & 9.9 & 132 & 18 & 2.1 & 18.2 \\
Concentrate & - & 15,840 & 9.21 & 229 & 5749 & 8656 & 351 & 10,926 \\
\hline
\end{tabular}

By comparing the results from Tables 4 and 5, it is observed that the treated solutions presented similar compositions. The recovery of chloride, HEDP and copper also showed to be similar for both conditions. The results indicated that, during the 6th cycle performed in the first test, the recovery of $\mathrm{K}^{+}$ions played major role. In addition, an important amount of energy was spent in the competition between the ion transfer from the dilute to the concentrate compartment and the backwards diffusion. Therefore, the five-cycle electrodialysis seemed to present more effectiveness in recovering copper chelates and HEDP from the synthetic rinsing waters.

For this reason, the concentrate obtained after the five-cycle continuous electrodialysis test was selected to prepare the electroplating solutions that will be discussed in Section 3.3. In addition, the treated solutions are able to be reused in the rinsing tanks. 
The main applications of electrodialysis in plating industry are wastewater treatment and metal recovery. In the last 15 years, $>50$ studies were published involving the use of electrodialysis for treating plating wastewaters [16]. Benvenuti et al. [17] evaluated the application of electrodialysis for the recovery of nickel ions from a plating wastewater and achieved a demineralization of $91 \%$ and $97 \%$ of nickel extraction. The obtained concentrate was used for replacing drag out losses without harming the quality of the deposits. $\mathrm{Lu}$ et al. [18] evaluated achieved $99.8 \%$ of $\mathrm{Ni}^{2+}$ extraction in a two-stage electrodialysis system. The concentrated solution contained 220 times more $\mathrm{Ni}^{2+}$ ions than the wastewater in its initial stage. These researches show that electrodialysis is a feasible technique for saving water and raw materials in plating industry. Moreover, the results from the present study indicate that chelated species may be submitted to membrane processes with similar efficiency than free cations.

\subsection{Analysis of the membrane electrochemical properties}

The properties of the anion-exchange membrane were evaluated before and after electrodialysis test and after two different cleaning procedures. In, it is presented the visual aspect of the membrane before electrodialysis and its structure visualized by means of SEM micrographs.

Backscattered electron images presented in Fig. 11 show that the HDX200 membrane has three different phases. The first phase is a structural reinforcement which can be completely visualized in Fig. 11(c) and is indicated by I in Fig. 11(b) and (d). The second phase is represented by the ion exchange particles, indicated by II in Fig. 11. The fixed ionic group in the HDX200 membrane is the quaternary ammonium which could be observed by the presence of nitrogen in the EDS analysis. The third phase is the inert binder, indicated by III in Fig. 11. Through the SEM/EDS analysis, it is seen that the structure of the HDX200 anionic membrane is characterized by clearly distinct conductive and nonconductive regions.

In Fig. 12, it is presented the visual aspect of the anion-exchange membrane immediately after an electrodialysis test (Fig. 12a) and after an acid-cleaning procedure (Fig. 12b).

The evaluated anion-exchange membranes were removed from the electrodialysis tests in the continuous system. Both membranes were placed between the dilute and the concentrate compartment during the electrodialysis tests. Each of them was forwarded to a different cleaning procedure, being one alkaline and one acid.

As it can be seen from Fig. 12, both cleaning procedures were capable of removing the superficial encrustation. The current-voltage curves for all the evaluated samples are presented in Fig. 13. In order to facilitate the analyses of the obtained results, the main properties of the CVC curves are summarized in Table 6.

In Table 6, R1 is the electric resistance obtained from the linear region of the CVCs; ilim is the limiting current density taken from the intersection between the linear region and the plateau region; Lpl is the plateau length and R3 is the electric resistance at overlimiting regimes. From Fig. 13 and Table 6, it is noticed that after electrodialysis, the ohmic resistance of the membrane increased about 3 times in comparison with the virgin membrane and its limiting current density was about 3 times lower. It is also noteworthy that the plateau length decreased after electrodialysis test. The mentioned modification 
regarding to the ohmic resistance, the limiting current density and the plateau length may be attributed either to deposition or chemical binding between the organic compound and the membrane functional groups [19].

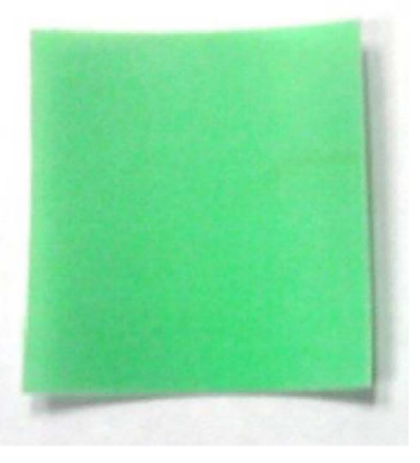

(a)

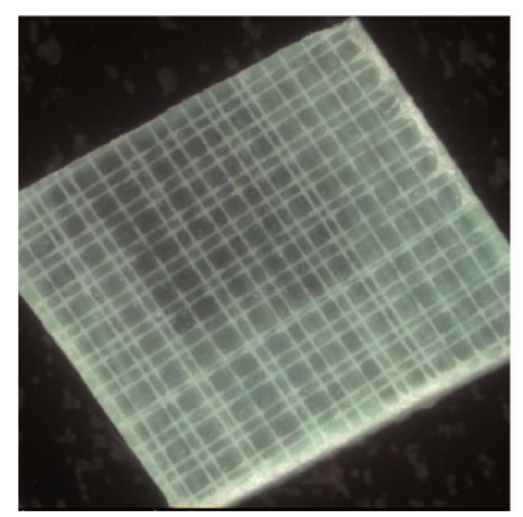

(c)

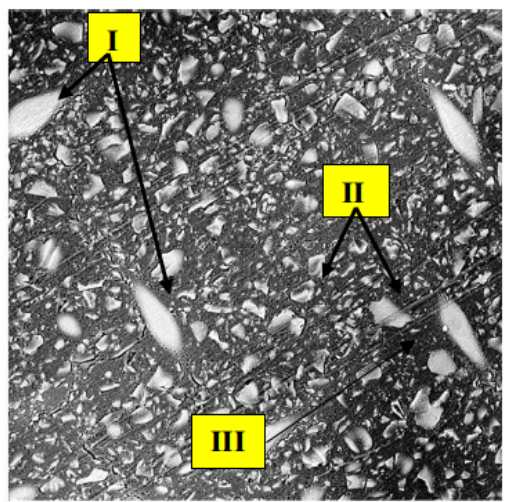

(b)

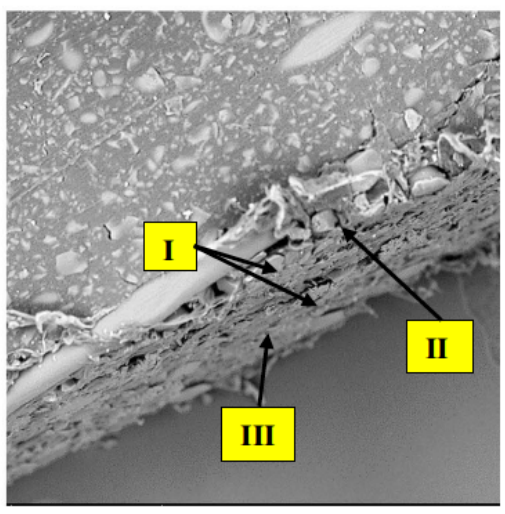

(d)

Fig. 11. Visual aspect (a) and backscattered electron images of HDX200 membrane. Figure (b) shows the membrane surface, Figure (c) shows the membrane reinforcement and Figure (d) presents the membrane cross section. In Figures (b) and (d), I represent the reinforcement fibers, II indicates the ion exchange particles and III indicates the inert binder.

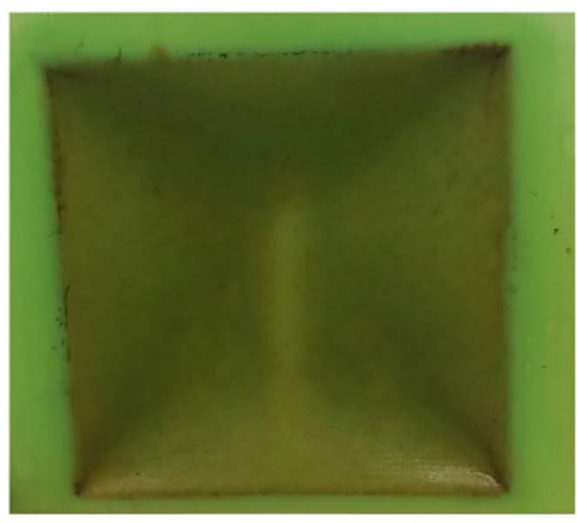

(a)

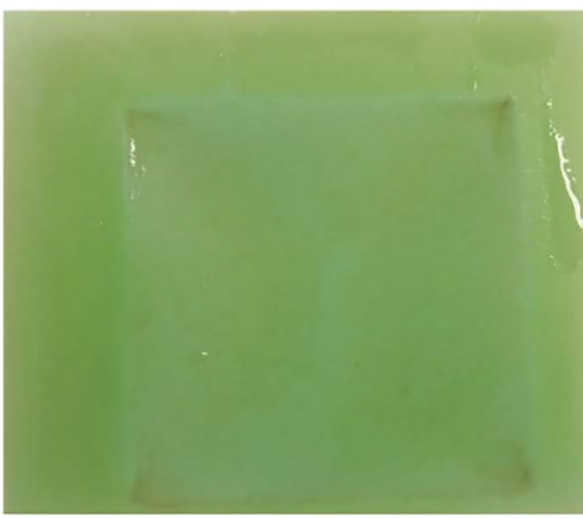

(b)

Fig. 12. Anion-exchange membrane after electrodialysis test (a) and after $\mathrm{H} 2 \mathrm{SO} 4-$ cleaning procedure (b). 
Table 6. Properties of the CVC curves for the anion-exchange membrane samples.

\begin{tabular}{llllll}
\hline AEM & $\mathrm{R}_{1}\left(\Omega \cdot \mathrm{cm}^{2}\right)$ & $\mathrm{i}_{\mathrm{lim}}\left(\mathrm{mA} \cdot \mathrm{cm}^{-2}\right)$ & $\mathrm{L}_{\mathrm{pl}}(\mathrm{V})$ & $\mathrm{R}_{3}\left(\Omega \cdot \mathrm{cm}^{2}\right)$ & $\mathrm{R}_{3} / \mathrm{R}_{1}$ \\
\hline Virgin & 183 & 0.62 & 1.54 & 2386 & 13.0 \\
After ED & 583 & 0.22 & 0.23 & 1408 & 2.4 \\
$\mathrm{H}_{2} \mathrm{SO}_{4}$ - cleaned & 435 & 0.34 & 0.34 & 1034 & 2.4 \\
KOH - cleaned & 435 & 0.34 & 0.13 & 608 & 1.4 \\
\hline
\end{tabular}

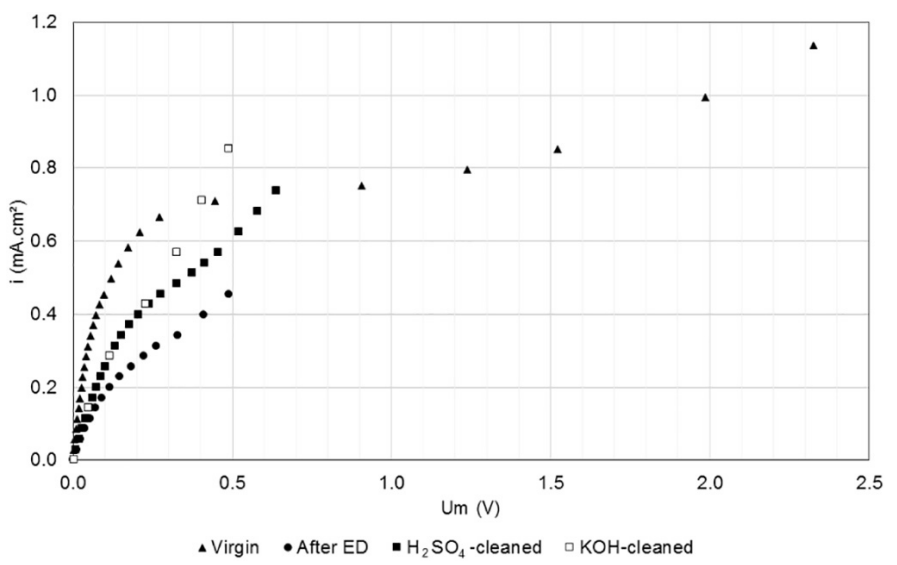

Fig. 13. Current-voltage curves obtained for the membrane samples.

After each of the cleaning procedures, it was observed an improvement of the CVC characteristics. Generally, the alkaline cleaning is more suitable for cleaning anionexchange membranes [20]. Nevertheless, both procedures presented similar efficiency for recovering part of the membrane properties. After the cleaning procedures, it was observed an increase of $54 \%$ of the limiting current density and a decrease in the ohmic resistance of about $25 \%$.

It may be observed that the most significant changes occurred in the region associated with the diffusion-controlled transport. In the CVCs presented in Fig. 13, the plateau length was reduced in the three curves related to the anion-exchange membrane after the electrodialysis tests. This indicates that the activation of the overlimiting mechanism was faster in these situations. This may suggest that the overlimiting mechanism suppresses the diffusion transfer. As reported by Elattar et al. [21], the plateau length of a CVC may be affected by the nature of the electrolyte and by the membrane surface. Since all the tests were performed using the same electrolyte, it is possible that the operating time or the interactions between the fixed groups and the HEDP or its chelates modified some of the active ion-exchange sites. Structural modifications of anion-exchange membranes due to ageing were observed by Choi and Moon [22]. The storage, the performance at overlimiting conditions and the reactions with weak acids may modify the quaternary ammonium fixed groups into weakly basic groups, such as tertiary or secondary amines, which present higher catalytic activity for water splitting [23].

To evaluate possible alterations in the membrane structure, FTIRATR analyses were performed after the alkaline cleaning procedure. The infrared spectra for virgin and cleaned HDX 200 membranes are shown in Fig. 14. 
Both spectra presented in Fig. 14 have similar aspects, which may indicate that few changes have occurred in the membrane structure during the electrodialysis tests. The spectrum related to the membrane after cleaning presented a peak in $1644 \mathrm{~cm}^{-1}$ and a group of peaks between $1150 \mathrm{~cm}^{-1}$ and $1250 \mathrm{~cm}^{-1}$ that were not present in the spectrum of the virgin membrane.

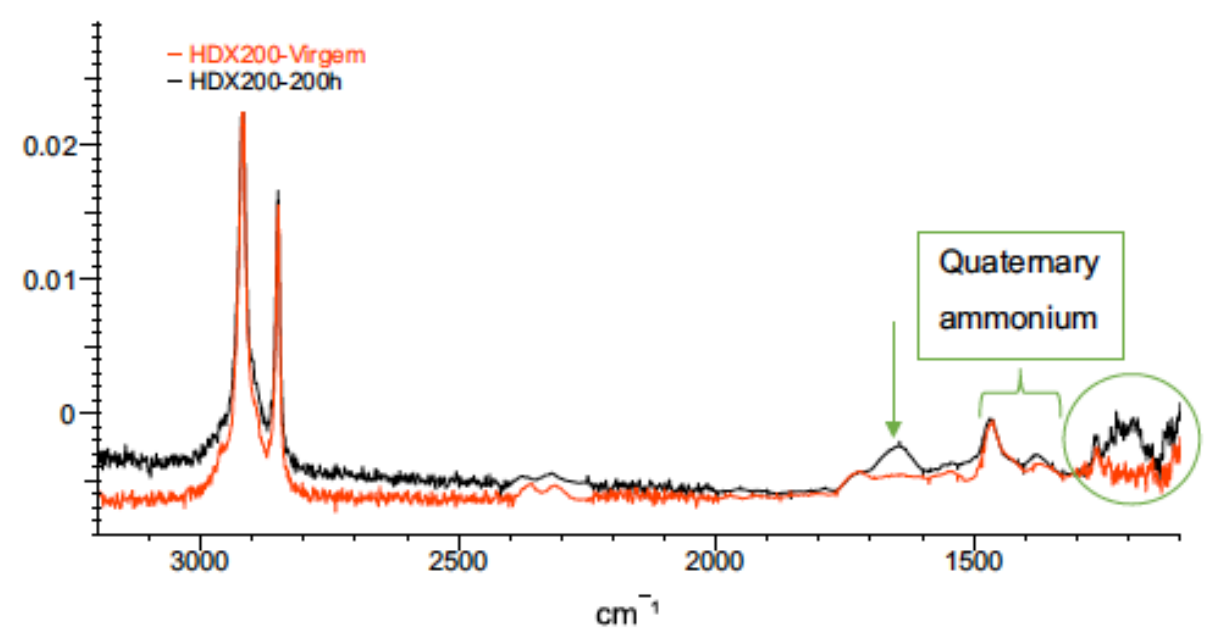

Fig. 14. IR spectra of the HDX 200 membrane. The orange spectrum represents the virgin membrane and the black spectrum represents the HDX 200 membrane after $130 \mathrm{~h}$ test and after alkaline cleaning.

According to Karas et al. [24], the two largest peaks at $2916 \mathrm{~cm}^{-1}$ and $2849 \mathrm{~cm}^{-1}$ are assigned to $\mathrm{C}-\mathrm{H}$ bonds. The vibrational lines that correspond to quaternary ammonium groups may be found at $1471 \mathrm{~cm}^{-1}$ and $1376 \mathrm{~cm}^{-1}$ and they can be observed for both membranes. Weakly basic groups are identified at wavelengths $834 \mathrm{~cm}^{-1}$ and $1300 \mathrm{~cm}^{-1}$. However, they were not observed in the spectra presented in Fig. 14. On the other hand, Zenobi et al. [25] reported that the ATR-FTIR spectra for HEDP presents a band at 1644 $\mathrm{cm}^{-1}$ related to the vibration of dissolved carbonate and water. A similar band was observed for the HDX-after-cleaning spectrum and it is identified with a green arrow in Fig. 14. In addition, a group of characteristic bands related to $\mathrm{PeO}$ bonds are found near $1150 \mathrm{~cm}^{-1}$. This region is identified with a green circle in Fig. 14 and it is possible to notice the differences between the spectrum for the virgin membrane and the spectrum for the cleaned membrane. Therefore, it seems that the differences observed in Fig. 13 are more related to the occurrence of strong bonds between the HEDP and the fixed groups than to the conversion of quaternary ammonium groups into weakly basic groups. In addition, the cleaning procedures indicated that these bonds may be reversible.

\subsection{HEDP degradation}

The degradation of HEDP into orthophosphate during electrodialysis was evaluated for long-term tests in continuous system. As previously mentioned, HEDP degradation into phosphate is an undesirable reaction in this application because the chelates may dissociate and release the copper ions. Samples of the solution from the concentrate compartment were collected at the end of each operating cycle and the concentration of orthophosphate was analyzed by means of ion chromatography, based on the conversion reaction proposed by Steber and Wierich [14] which states that HEDP may be degraded into acetate and orthophosphate in the presence of natural or artificial UV light. As it is 
presented in Fig. 15, all the samples from the concéntrate compartment presented a percent degradation smaller than $2 \%$.

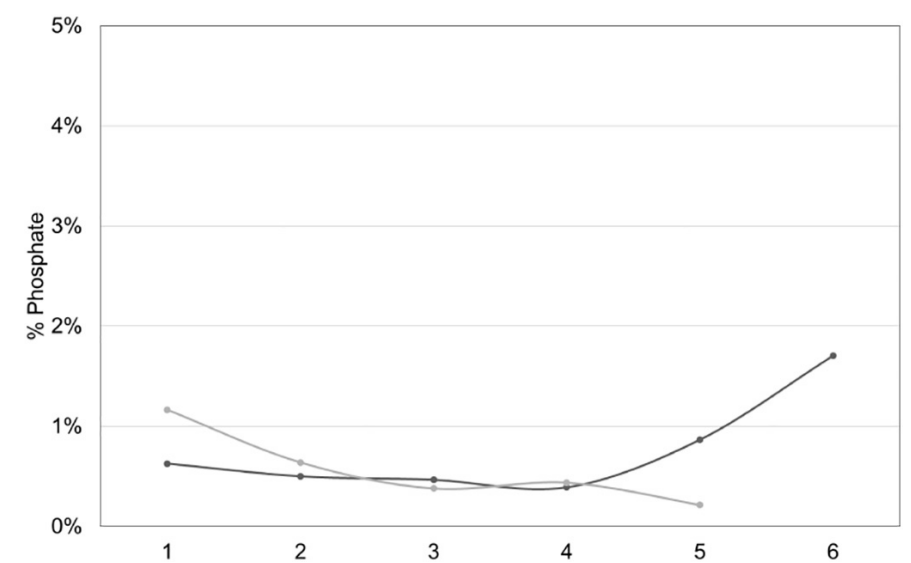

Fig. 15. Degradation of HEDP into orthophosphate in the samples of the concentrate compartment after each of the operating cycles for both ED tests.

In Fig. 15, the y-axis shows the percent of HEDP converted into phosphate and the x-axis shows the operating cycle of the analyzed sample. Both curves represent the concentrate solution after finishing an operating cycle. The six cycles test (darker curve) was performed during $220 \mathrm{~h}$ and the five cycles test (lighter curve) was performed during 130 $h$. The degradation of HEDP was evaluated because the conversion of organic phosphorus into orthophosphate could reléase the chelates and, therefore, could reduce the recovery of copper chelates. The results from Fig. 15 suggested that the electrodialysis process did not cause HEDP degradation in the concentrate solution after long-term tests.

\subsection{Electrodeposition tests}

The concentrate solution from the five-cycle electrodialysis test carried out in the continuous system was used to prepare the electroplating solutions. Firstly, deposition tests were performed using the original HEDP-based copper bath. Then, electrolytes containing the HEDP-based bath and the concentrate from electrodialysis were prepared with different amounts of concentrate. The copper coatings obtained from the depositions with the mixed electrolytes were compared to the coatings obtained with the HEDP-based bath solution. This procedure was performed in order to simulate the replacement of ions from the original bath that may be lost due to drag-out.

The average area of the test specimens was $17.8 \pm 0.2 \mathrm{~cm}^{2}$. The calculated current to be applied was $53.4 \pm 0.6 \mathrm{~mA}$, thus a current of $53 \mathrm{~mA}$ was applied in all deposition tests, taking into account that the current density to be applied in the electrodeposition tests was established in $0.3 \mathrm{~A} \cdot \mathrm{dm}^{-2}$ by Pecequilo [26].

Table 7 presents the calculated compositions of the electrolytes used for copper depositions tests, based on the theoretical composition of the original bath.

The obtained coatings were analyzed by means of visual tests, SEM/EDS microscopy and adherence tests according to the ASTM D3359-07 [27] standard. 
The visual tests showed bright and uniform coatings after all deposition tests using the six electrolytes described in Table 6 . The visual aspect of all test specimens after the adherence test is shown in Fig. 16.

Table 7. Composition of the mixed electrolytes, calculated based on the theoretical composition of the original bath.

\begin{tabular}{|c|c|c|c|c|c|c|c|}
\hline \multirow[t]{2}{*}{ Solution } & \multirow[t]{2}{*}{$\%$ of concentrate from ED } & \multicolumn{5}{|c|}{ Composition $\left(\mathrm{mg} \cdot \mathrm{L}^{-1}\right)$} & \multirow[t]{2}{*}{ HEDP: $\mathrm{Cu}^{2+}$ ratio } \\
\hline & & $\mathrm{Cu}^{2+}$ & HEDP & $\mathrm{K}^{+}$ & $\mathrm{Cl}^{-}$ & $\mathrm{SO}_{4}{ }^{2-}$ & \\
\hline $100 / 0^{a}$ & 0 & 4500 & 105,000 & 7000 & 7000 & 6807 & 7.2 \\
\hline $90 / 10$ & 10 & 4073 & 95,075 & 7393 & 6335 & 6992 & 7.2 \\
\hline $80 / 20$ & 20 & 3646 & 85,150 & 7785 & 5670 & 7177 & 7.2 \\
\hline $70 / 30$ & 30 & 3219 & 75,225 & 8178 & 5005 & 7362 & 7.2 \\
\hline $60 / 40$ & 40 & 2791 & 65,300 & 8570 & 4340 & 7547 & 7.2 \\
\hline $50 / 50$ & 50 & 2364 & 55,375 & 8963 & 3676 & 7732 & 7.2 \\
\hline
\end{tabular}

${ }^{\mathrm{a}}$ Theoretical composition.

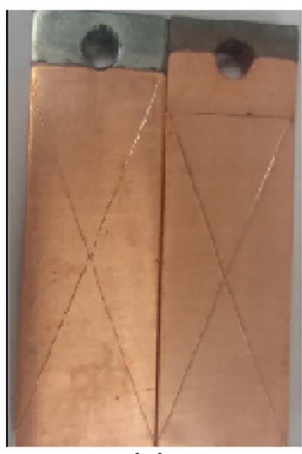

(a)

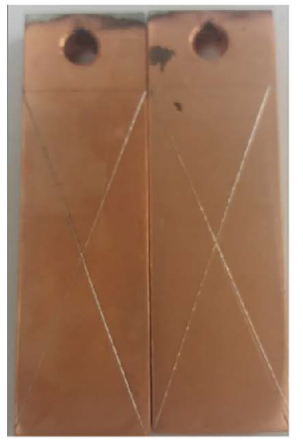

(d)

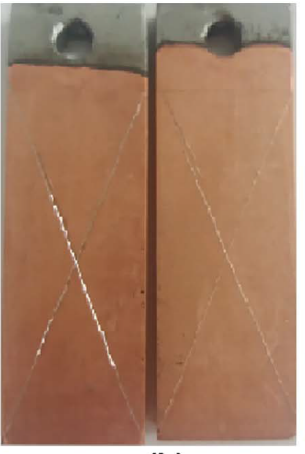

(b)

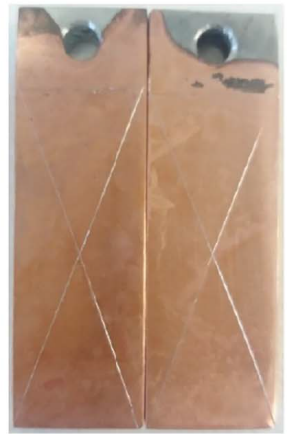

(e)

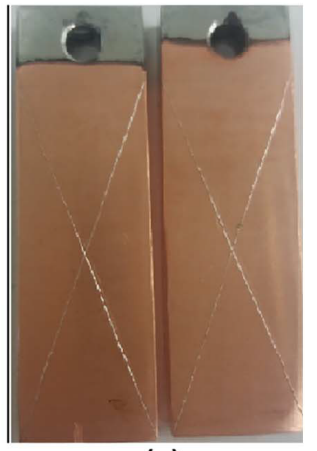

(c)

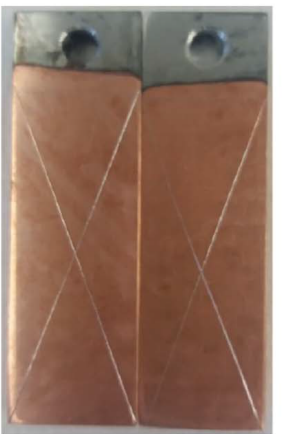

(f)

Fig. 16. Visual aspect of the test specimens after the adherence test. Plating solutions: (a) original bath; (b) mixed electrolyte (90/10); (c) mixed electrolyte (80/20); (d) mixed electrolyte (70/30); (e) mixed electrolyte (60/40) and (f) mixed electrolyte (50/50).

The results from the adherence tests showed that the test specimens may be qualitatively classified according the mentioned standards as "less than $5 \%$ of percent area removed" or "detachment up to $1 \mathrm{~mm}$ along the cut", which suggested similar adherence effectiveness between the original bath and all the mixed electrolytes.

Complementary analyzes were carried out by SEM microscopy using the test specimens coated with the original bath and with the electrolyte containing $50 \% \mathrm{v} / \mathrm{v}$ of the concentrate from electrodialysis. Measurements performed in five different points indicated that the average thickness of the copper layer was $3.4 \mu \mathrm{m}$ for the original bath 
and the thickness of the coating decreases as the amount of recycled solution increases. The average thickness of the copper coating for the 50/50 electrolyte was $0.74 \mu \mathrm{m}$. The microscopy analyses carried out in the copper coating obtained from the mixed (50/50) electrolyte showed that the obtained coating seems to have similar uniformity than the coating obtained from the original bath, but a greater number of micropores, as detailed in Fig. 17.

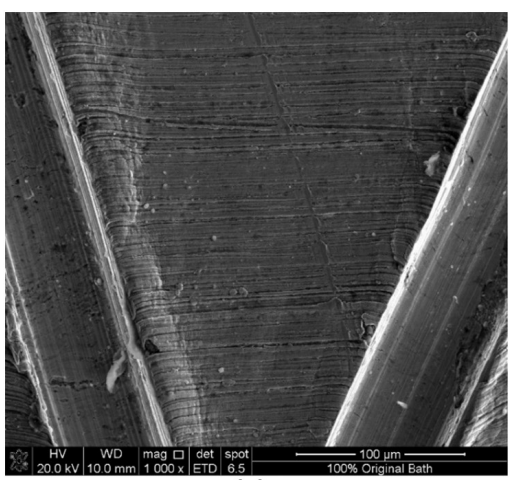

(a)

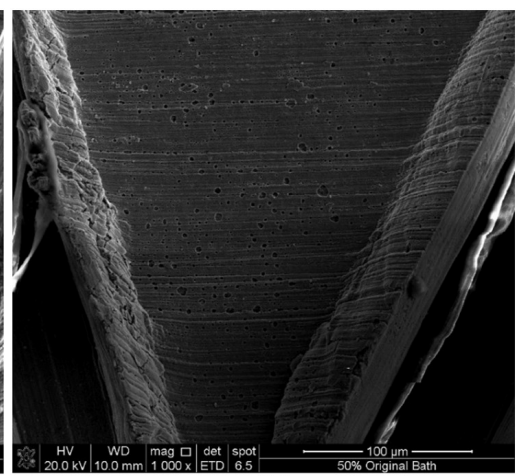

(b)

Fig. 17. Backscattered electron images obtained by SEM showing the coated surface near the X-shaped cut of the test specimen coated with (a) $100 \%$ original bath and (b) $50 \%$ concentrate from ED.

SEM analyses of the coatings obtained with the original bath showed the presence of pores with an average diameter of $0.5 \mu \mathrm{m}$. It was noticed that the pores were evenly distributed over the surface, presented a well-defined round shape and had similar sizes. They were probably formed because of the reaction of hydrogen reduction at the cathode surface. For the mixed electrolyte, the pores were randomly distributed and had an average diameter of $1.9 \mu \mathrm{m}$.

\section{Conclusions}

In this work, the possibility of obtaining a concentrated solution from a model rising water containing $\mathrm{Cu}(\mathrm{II})$-HEDP chelates was evaluated. After long-term electrodialysis tests performed using the laboratory-scale system, it was possible to obtain a concentrated solution containing 5 to 6 times more copper and HEDP ions that the initial one. After each of the five operating cycles, the percent demineralization was close to $90 \%$ and the percent extraction of ions was higher $\tan 80 \%$. At the end of five operating cycles, the conductivity gradient between the concentrate and the dilute solutions became high enough to cause a backward diffusion decreasing the percent demineralization. Thus, the adopted configuration in the laboratory-scale stack allowed the production of treated water and a concentrate solution with the following compositions: the average composition of the treated solutions was $7 \mathrm{mg}\left(\mathrm{Cu}^{2+}\right) \cdot \mathrm{L}^{-1} ; 144 \mathrm{mg}(\mathrm{HEDP}) \cdot \mathrm{L}^{-1} ; 34 \mathrm{mg}\left(\mathrm{K}^{+}\right)$ $\cdot \mathrm{L}^{-1} ; 4 \mathrm{mg}\left(\mathrm{Cl}^{-}\right) \cdot \mathrm{L}^{-1}$ and $9 \mathrm{mg}\left(\mathrm{SO}_{4}{ }^{2-}\right) \cdot \mathrm{L}^{-1}$, with an average conductivity of $170 \mu \mathrm{S} \cdot \mathrm{cm}^{-1}$. The treated solutions could be reused in the rinsing tanks, promoting water reclamation. The composition of the concentrate solution was $229 \mathrm{mg}\left(\mathrm{Cu}^{2+}\right) \cdot \mathrm{L}^{-1} ; 5749$ $\mathrm{mg}(\mathrm{HEDP}) \cdot \mathrm{L}^{-1} ; 10,926 \mathrm{mg}\left(\mathrm{K}^{+}\right) \cdot \mathrm{L}^{-1} ; 351 \mathrm{mg}\left(\mathrm{Cl}^{-}\right) \cdot \mathrm{L}^{-1}$ and $8656 \mathrm{mg}\left(\mathrm{SO}_{4}{ }^{2-}\right) \cdot \mathrm{L}^{-1}$, with a conductivity of $15.84 \mathrm{mS} \cdot \mathrm{cm}^{-1}$.

After the long-term electrodialysis tests, the properties of the membranes were compared to a virgin membrane, before and after two different cleaning procedures - one acid and 
one alkaline. The results showed that possible interactions between the organic acid and the membrane fixed groups may have affected the evaluated properties. Both cleaning procedures presented similar performance and were capable of partially restoring the membrane properties, suggesting that the $\mathrm{P}$ bonds may be reversible.

The degradation of HEDP during electrodialysis tests was evaluated. Results showed that throughout the long-term electrodialysis, the degradation of HEDP was lower than $2 \%$.

Lastly, Zamak test specimens were coated in an electroplating cell using the mixed electrolytes prepared with the concentrate from electrodialysis. The copper coatings were evaluated by means of visual tests, adherence tests and SEM/EDS microscopy. The mixed electrolytes containing up to $50 \%$ of the concentrate were able to produce bright, uniform and adherent copper coatings.

SEM analyses indicated that the occurrence of micropores in the coatings may increase with the increase of the concentrate obtained by electrodialysis. In industrial scale, the addition of the concentrate solution may not achieve $50 \% \mathrm{v} / \mathrm{v}$, because of a number of contaminants and variables that depend on each manufacturing unity and are difficult to be totally predicted in laboratory-scale. Nevertheless, the results indicated that the concentrate solution may be used to replace drag-out losses from the bath. Thus, the application of electrodialysis may be a feasible alternative for recovering water and inputs from the evaluated solution, reducing the waste (and wastewater) generation and saving natural resources.

\section{Acknowledgements}

Authors would like to thank the Institute for Technological Research (IPT), the Institute for Technological Research Foundation (FIPT), to the São Paulo Research Foundation (Fapesp - processes 2012/51871-9, 2016/17527-0 and 2014/13351-9) and the National Council for Scientific and Technological Development.

\section{References}

[1] Z. Panossian, Corrosão e proteção contra corrosão em equipamentos e estruturas metálicas, 1. ed., Vol. 2 IPT, São Paulo, 1993 (ISBN 8509000999).

[2] C.V. Pecequilo, Z. Panossian, Study of copper electrodeposition mechanism from a strike alkaline bath prepared with 1-hydroxyethane-1,1-diphosphonic acid through cyclic voltammetry technique, Electrochim. Acta 55 (2010) 3870-3875, http://dx.doi.org/10.1016/j.electacta.2010.01.113.

[3] A.T.K. Tran, P. Mondal, J. Lin, B. Meesschaert, L. Pinoy, B. Van Der Bruggen, Simultaneous regeneration of inorganic acid and base from a metal washing step wastewater by bipolar membrane electrodialysis after pretreatment by crystallization in a fluidized pellet reactor, J. Membr. Sci. 473 (2015) 118-127, http://dx.doi.org/10.1016/j.memsci.2014.09.006.

[4] S. Caprarescu, D.I. Vaireanu, A. Cojocaru, I. Maior, V. Purcar, A 3-cell electrodialysis system for the removal of copper ions from electroplating wastewater, Optoelectron. Adv. Mater. 5 (2011) 1346-1351.

[5] S. Chen, C. Li, H. Hsu, P. Lee, Y. Chang, C. Yang, Concentration and purification of chromate from electroplating wastewater by two-stage electrodialysis processes, 
J. Hazard. Mater. $161 \quad$ (2009) 1075-1080,

http://dx.doi.org/10.1016/j.jhazmat.2008.04.106.

[6] I. Frenzel, D.F. Stamatialis, M. Wessling, Water recycling from mixed chromic acid waste effluents by membrane technology, Sep. Purif. Technol. 49 (2006) 76-83, http://dx.doi.org/10.1016/j.seppur.2005.08.010.

[7] D.E. Crotty, D.E. Bailey, Electrodialysis of electroless nickel process solutions: continuous versus batch treatment designs, Met. Finish. 100 (2002) 30-39.

[8] C.L. Li, H.X. Zhao, T. Tsuru, D. Zhou, M. Matsumura, Recovery of spent electroless nickel plating bath by electrodialysis, J. Membr. Sci. 157 (1999) 241249.

[9] National Research Council, Committee on small water supply systems, safe wáter from every tap, Improving Water Service to Small Communities, 1997, http://dx.doi.org/10.17226/5291.

[10] K. Westerling, ED vs. RO: The Benefits of Electrodialysis For Desalination, (2015), pp. 1-2 (https://www.wateronline.com/doc/ed-vs-ro-the-benefitsofelectrodialysis-for-desalination-0001 (accessed May 20, 2017)).

[11] OSMO, ® Membrane systems, technology overview: Electrodialysis, At: www.osmomembrane.de/en/technology/electro-dialysis.html.

[12] T. Scarazzato, D.C. Buzzi, A.M. Bernardes, J.A.S. Tenorio, D.C.R. Espinosa, Treatment of wastewaters from cyanide-free plating process by electrodialysis, J. Clean. Prod. 91 (2014) 241-250, http://dx.doi.org/10.1016/j.jclepro.2014.12.046.

[13] T. Scarazzato, D.C. Buzzi, A.M. Bernardes, D.C.R. Espinosa, Current-voltage curves for treating effluent containing HEDP: determination of the limiting current, Braz.J. Chem. Eng. 32 (2015) 831-836.

[14] J. Steber, P. Wierich, Properties of hydroxyethane diphosphonate affecting its environmental fate: degradability, sludge adsorption, mobility in soils, and bioconcentration, Chemosphere 15 (1986) 929-945, http://dx.doi.org/10.1016/0045-6535(86)90058-5 (7).

[15] T. Scarazzato, Z. Panossian, E.M. Ortega, J.A.S. Tenório, D.C.R. Espinosa, Evaluation of the transport properties of copper ions through a heterogeneous ionexchange membrane in etidronic acid solutions by chronopotentiometry, J. Membr. Sci. 535 (2017) 268-278, http://dx.doi.org/10.1016/j.memsci.2017.04.048.

[16] T. Scarazzato, Z. Panossian, J.A.S. Tenório, V. Pérez-Herranz, D.C.R. Espinosa, A review of cleaner production in electroplating industries using electrodialysis, J. Clean. Prod. 168 (2017) 1590-1602, http://dx.doi.org/10.1016/j.jclepro.2017.03.152.

[17] T. Benvenuti, M.A. Siqueira Rodrigues, A.M. Bernardes, J. Zoppas-Ferreira, Closing the loop in the electroplating industry by electrodialysis, J. Clean. Prod. (2016), http://dx.doi.org/10.1016/j.jclepro.2016.05.139.

[18] H. Lu, Y. Wang, J. Wang, Recovery of Ni2+ and pure water from electroplating rinse wastewater by an integrated two-stage electrodeionization process, J. Clean. Prod. 92 (2015) 257-266, http://dx.doi.org/10.1016/j.jclepro.2014.12.056.

[19] H. Lee, M. Hong, S. Han, J. Shim, S. Moon, Analysis of fouling potential in the electrodialysis process in the presence of an anionic surfactant foulant, J. Membr. Sci. 325 (2008) 719-726, http://dx.doi.org/10.1016/j.memsci.2008.08.045.

[20] S. Mikhaylin, L. Bazinet, Fouling on ion-exchange membranes: classification, characterization and strategies of prevention and control, Adv. Colloid Interf. Sci. 229 (2016) 34-56, http://dx.doi.org/10.1016/j.cis.2015.12.006.

[21] A. Elattar, A. Elmidaoui, N. Pismenskaia, Comparison of Transport Properties of Monovalent Anions through Anion-Exchange Membranes, (1998), p. 143. 
[22] J.H. Choi, S.H. Moon, Structural change of ion-exchange membrane surfaces under high electric fields and its effects on membrane properties, J. Colloid Interface Sci. 265 (2003) 93-100, http://dx.doi.org/10.1016/S0021-9797(03)00136-X.

[23] N.D. Pismenskaya, V.V. Nikonenko, E.I. Belova, G.Y. Lopatkova, P. Sistat, G. Pourcelly, K. Larshe, Coupled convection of solution near the surface of ionexchange membranes in intensive current regimes, Russ. J. Electrochem. 43 (2007) 307-327, http://dx.doi.org/10.1134/S102319350703010X.

[24] F. Karas, J. HNát, M. Paidar, J. Schauer, K. Bouzek, Determination of the ionexchange capacity of anion-selective membranes, Int. J. Hydrog. Energy 39 (2014) 5054-5062, http://dx.doi.org/10.1016/j.ijhydene.2014.01.074.

[25] M.C. Zenobi, C.V. Luengo, M.J. Avena, E.H. Rueda, An ATR-FTIR study of different phosphonic acids in aqueous solution, Spectrochim. Acta A Mol. Biomol. Spectrosc. 70 (2008) 270-276, http://dx.doi.org/10.1016/j.saa.2007.07.043.

[26] C.V. Pecequilo, Z. Panossian, Improvement to cyanide-free, alkaline copper strike bath, for achieving improved, satisfactory adhesion to Zamak alloys and increasing brightness. Patent WO2011011845A1, 2011.

[27] American Society for Testing and Materials, D3359-07, Standard Test Methods for Measuring Adhesion by Tape Test, ASTM, 2013, http://dx.doi.org/10.1520/D335909E02.2. 